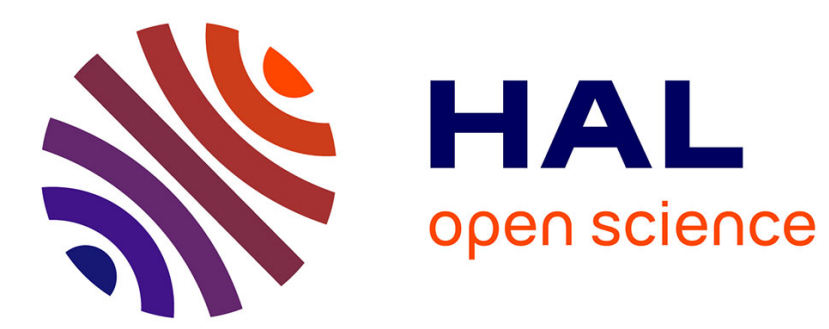

\title{
Prospects for a second generation supersonic transport
}

S. Swadling

\section{To cite this version:}

S. Swadling. Prospects for a second generation supersonic transport. Journal de Physique IV Proceedings, 1993, 03 (C7), pp.C7-11-C7-30. 10.1051/jp4:1993702 . jpa-00251708

\section{HAL Id: jpa-00251708 https://hal.science/jpa-00251708}

Submitted on 1 Jan 1993

HAL is a multi-disciplinary open access archive for the deposit and dissemination of scientific research documents, whether they are published or not. The documents may come from teaching and research institutions in France or abroad, or from public or private research centers.
L'archive ouverte pluridisciplinaire HAL, est destinée au dépôt et à la diffusion de documents scientifiques de niveau recherche, publiés ou non, émanant des établissements d'enseignement et de recherche français ou étrangers, des laboratoires publics ou privés. 


\title{
Prospects for a second generation supersonic transport
}

\author{
S.J. SWADLING
}

British Aerospace Airbus Limited

\section{INTRODUCTION}

I have chosen as the theme of this lecture "Prospects for a Second Generation Supersonic Transport". This is a very large subject and I shall be able to cover only some of the key areas.

The starting point has to be Concorde as this represents the first generation of Supersonic transport and is the only civil supersonic transport in operation today.

My aim is briefly to review Concorde and to try to put it into context, identifying both the good and the bad aspects of that programme. From this I shall extract the major lessons that we have learned over the 30 years or so since Concorde was first a gleam in our technical eyes.

This leads naturally into the requirements and prospects for a successor to Concorde and I shall deal with the likely market for the aircraft, the technology standards required and the environmental issues.

In particular as this paper is part of a conference devoted to "Materials for Aerospace Applications" I will deal with the possible material choices for both airframe and engine in some detail.

Lastly, there is the question when, or perhaps if, a successor is likely to go into service and how such a project is to be brought to fruition.

THE LESSONS FROM CONCORDE

Starting with Concorde it is clear that its unique position as the only civil supersonic transport in service makes it an important stepping stone towards a successor.

To set the scene it is worth noting a few statistics related to Concorde. To date the combined fleets of British Airways and Air France have between them achieved around 49,000 supersonic flights and around 100,000 supersonic flight hours. In fact this means that Concorde has more Mach 2 experience than the combined airforces of all the NATO countries. 
This has been achieved with a very good safety record but with some problems with despatch reliability where typically Concorde achieves around $93 \%$ or $94 \%$ of flights despatched within 15 minutes of schedule, whereas current subsonic aeroplanes achieve around $99 \%$. It is also worth noting that Concorde requires roughly four times the maintenance hours that are necessary to keep a Boeing 747 flying.

Looking at the pros and cons of Concorde, Figure 1, on the plus side: Concorde regularly carries a 10 ton payload over 3,500 nautical miles at Mach 2.05: it operates within the existing air traffic control patterns set by the subsonic fleet: it is well liked by the passengers. Against this there are some significant debits: in today's world it is a noisy aeroplane compared to the modern subsonic jets designed to meet the current stringent noise requirements: the sonic boom the aircraft produces is judged to be unacceptable over populated areas: the emissions of nitrogen oxides are relatively high compared to the subsonic aeroplane because of the high fuel burn: lastly it was a very long, high cost, high risk development undertaken with a high level of government support.

Starting from this basis one can establish an initial list of requirements for a second generation supersonic transport, Figure 2 . First and foremost the aircraft has to be capable of earning a satisfactory commercial return for both the manufacturers and the airlines that will operate it in passenger service: as for Concorde the aeroplane must be capable of operating in the air traffic patterns and airport infrastructure that will be determined by the subsonic fleet in the early part of the next century: the despatch reliability will have to be comparable with the subsonic fleet: the environmental requirements in force at the time of entry-into-service, both noise and emissions, will have to be met: the programme costs and risks must be controlled.

\section{THE POTENTIAL MARKET}

Turning next to the market prospects for a successor to Concorde, our first problem is to forecast what is the size of the passenger traffic in the first decades of the 21 st century. This is an activity undertaken by all major companies in the aviation business and there are a number of highly complex methodologies used. They all take into account expected and different growth of economies of various areas of the world and other factors such as fuel costs etc., and eventually arrive at an estimate of the total number of passenger seats that are required to meet the likely demands of the travelling public. There is broad consensus from the various estimates and we are looking at trebling passenger traffic from 1990 to 2010 and a further doubling between 2010 and 2030 .

Current BAe studies of the market for the supersonic transport have concentrated on the top 150 routes. These routes have been identified using today's timetables and ranking the capacities offered on all sectors greater than 2000 nautical miles. Routes flown entirely over populated land have been removed, for example US Transcontinental. These 150 routes represent approximately $60 \%$ of today's long haul capacity. By 2010 , taking into account the need to offer high frequency supersonic services, these routes represent a much higher proportion of the supersonic market.

2000 nautical miles was arbitrarily chosen as a minimum cut-off range because the supersonic transport obviously achieves greater time savings on the longer flights. However, airlines will operate on shorter 
sectors where traffic demand is high and the time savings are significant.

Projections for inter-regional traffic growth are shown in Figure 3. These have been applied to each of the top 150 routes to determine the passenger traffic in 2010. It is assumed from 2010 to 2030 that growth rate is constant at $3.5 \%$. These traffic growth projections are illustrated on Figure 4. It is of interest to note that, due to the higher growth rates on the North America to Asia routes, by 2010 these routes have more traffic than the North Atlantic, which is today's dominant long-haul market. Both the North Pacific and North Atlantic with their long overwater segments are ideally suited to supersonic operations.

Although the total traffic in the early 21st century can be predicted, the split of this traffic into each fare category - first, business, economy etc. - is more difficult to forecast. This split is required as each class of traffic will react in a different way to supersonic time savings and fare premiums. First class traffic is currently growing at only about one-third of the rate of the total traffic and some airlines today are removing this class of seating altogether. Similarly business class in some regions of the world is growing at about $80 \%$ of the total, although several airlines are re-configuring their aircraft seating to improve the quality of business class.

The main driver of traffic growth is tourism and today this is growing at $115 \%$ of the total traffic. Figure 5 illustrates the effect of these trends on the market in 2010 with first and business classes reducing as a percentage of the total traffic. If these trends are maintained, future aircraft could be configured in only two classes, or indeed another form of three class layout would be established consisting of business, superior economy and excursion. No doubt these classes will be re-defined by some new market orientated titles.

The next task is to identify the share of the total market that can be reasonably expected to be taken by a new supersonic transport. This has to recognise the inevitable in that a supersonic aircraft is almost certainly more expensive for an airline to buy and operate than a contemporary subsonic vehicle, although this is, to some degree, offset by the greater productivity arising from its speed. Hence it is likely that a fare premium will be required.

Elasticity of demand with fare increases will be different for each class of traffic. The most inelastic, $i . e$. least sensitive to fare increase, is predicted to be the first, business and full fare economy passenger whereas the economy excursion and restricted economy excursion passengers are expected to be very sensitive to fare surcharges. The assessed reduction in traffic with increased fare levels are shown on Figure 6. These elasticities are for today's passengers however.

With the increased GDP and hence disposable income inherent in the traffic forecast, it could be assumed that tomorrow's passengers will be prepared to pay a higher supersonic surcharge than todays. Studies are being initiated to try and evaluate both today's and tomorrow's passengers' elasticities. These elasticities are assumed to apply on routes where the supersonic service achieves a time saving of $50 \%$. The penetration of the market is assumed to be reduced with less time saving with no transfer from subsonic to supersonic with zero timesaving.

Applying these fare elasticities to the traffic forecast for the top 150 routes, the number of passengers in each class can be estimated in 2030 
for a range of fare surcharges, Figure 7 . The size of the supersonic aircraft fleet can now be estimated. The results of this analysis suggest that a reasonable sized aircraft of, say, 280 seats would result in a fleet size of some 1,600 aircraft at a zero fare premium. As the premium is increased, so the share of the market falls until, at $45 \%$, the fleet size would reduce to some 300 aircraft, Figure 8 .

At this stage the exercise is essentially theoretical as it assumes that we can design and build an aeroplane that can be sold and operated profitably at each of the fare premiums in the range we have assumed.

\section{TECHNOLOGY STANDARDS}

This leads naturally into the question of technology standards. For study purposes we have established a datum standard based on the research work carried out since Concorde was designed. This suggests that relative to Concorde supersonic aerodynamic drag can improve by $20 \%$, structural efficiency by $40 \%$, supersonic cruise specific fuel consumption from the engine by $3 \%$ and installed thrust to weight ratio of the powerplant by $17.5 \%$, Figure 9 . This latter figure allows for the significant amount of weight and complexity that will have to be introduced to the powerplant to enable the aircraft to meet today's stringent noise requirements.

At first sight these figures are surprisingly large. However, one has to remember that Concorde technology is now approaching 25 years old.

At the time we were designing Concorde there was no high powered computing as we know it today. Our mainframe computers of the time are equivalent to a desk top PC of today. This severely limited our ability to optimise both aerodynamic and structural design.

In the systems field the aircraft predates the revolution brought about by digital avionics. The one exception to this being the air intake control system which went through several re-designs culminating in the digital system on the aircraft today.

The aircraft also pre-dates the widespread use of lightweight fibre reinforced resin materials, being almost entirely made of metallic structures. The predominant material being based on the RR5 8 piston aluminium alloy.

The datum standard we have established is well founded and takes full advantage of the advances made in the use of high powered computers to optimise both aerodynamics and structural design.

Perhaps the most striking figure is the $40 \%$ improvement targeted for the airframe structure relative to Concorde and the $20 \%$ improvement in the engine thrust to weight ratio relative to the olympus 593 .

As a starting point is is worth reflecting on the dominant difference between a subsonic and a supersonic aircraft, $i . e$. the effects of kinetic heating on the aircraft. Figure 10 shows how the aircraft temperature rises with increase in cruise Mach No. Two curves are shown. The upper curve is the so-called stagnation temperature which represents the temperature at the nose of the aircraft and also the temperature of the air at entry to the engine. The lower curve is typical of the general surface temperature reached by the airframe, the reduction in temperature resulting from the effects of radiation to the atmosphere. 
Dealing first with the airframe structure it is clear that the effects of both the actual temperature and long term high temperature soak on material properties have to be allowed for in the normal design processes, i.e. static strength both tensile and compressive, fatigue and damage tolerance etc. There are, however, two other phenomena that have to be allowed for. Firstly the thermal stresses caused by temperature gradients within the structure which can arise as standing stresses due to the presence of cold areas such as fuel tank boundaries or transient effects due to the delay in heating of structures remote from the heated surface. Secondly there is the effect known as creep when at stress levels well below the normal elastic limit the material slowly deforms permanently. This permanent deformation can reduce the static strength levels or in extreme cases proceed to failure.

Turning to the topic of materials selection we first have to identify the cruise Mach NO. of the aircraft. Our datum position is to use the same cruise Mach No, as Concorde, $M=2.05$ at ISA conditions. At this Mach No. we anticipate general structural temperatures to be between $90^{\circ} \mathrm{C}$ and $100^{\circ} \mathrm{C}$ with only local areas approaching the full stagnation temperature of $127^{\circ} \mathrm{C}$. We are however also studying higher cruise Mach Nos. up to $M=2.4$ or perhaps 2.5. For these Mach Nos. we anticipate general structural temperatures of perhaps $150^{\circ} \mathrm{C}$ to $160^{\circ} \mathrm{C}$ and local areas up to $220^{\circ} \mathrm{C}$.

For the airframe we are looking at three generic classes of materials as potential candidates, conventional metal alloys, organic matrix composites and advanced metallic materials including metal matrix composites.

For the conventional wrought alloys the Aluminium Lithium alloys show some promise of achieving our targeted savings at least at the lower end of our possible Mach No, range. Titanium alloys such as Ti 6 A14V and Ti $4 \mathrm{Al} 4$ Mo $25 \mathrm{n}$ potentially could offer this order of saving over the whole Mach No. range, but are of higher density which places them at a disadvantage compared to Aluminium due to the relatively low loading index of a delta wing aircraft and the consequent1y light scantlings. This could be to some extent offset by use of lightweight structural concepts such as honeycomb panels but at the expense of higher production costs.

For organic matrix composite materials todays toughened epoxy resin matrices are probably marginal on temperature capability but would provide the required improvement in strength and weight. For the lower end of our Mach No. range it is possible that cyanate ester matrices will perform satisfactorily and for the upper end of the range bismaleimides should be adequate. These latter materials are already in use in the military field and are expected to more than meet our required performance target. There is, however, a question mark against the manufacturing process and costs when used for large structures.

Turning now to the advanced metallics we have developments such as aluminium alloys produced by evaporative alloying techniques and the Silicon Carbide or Boron fibre reinforced metal matrix composites. The evaporated aluminium alloys possess very good heat resistance, creep performance and corrosion resistance and should meet our target improvement. There are, however, questions over our ability to move from essentially laboratory scale production to sizes associated with our projected aeroplane. Silicon Carbide fibres in an aluminium matrix appears to offer very good performance, potentially well in excess of our target improvement, but with manufacturing problems to be resolved, not to mention questions over costs. 
In summary, therefore, for the airframe there are several candidate materials but choosing between them will depend on the eventual choice of cruise Mach No. and the usual trade off between technical performance and cost.

For the engine we see a very similar picture to the airframe where the effects of kinetic heating fundamentally change key design parameters.

For a typical subsonic engine the take-off regime is critical combining maximum rpm, maximum compressor exit temperature and maximum turbine inlet temperature, but lasting only for around two minutes. For the cruise phase of flight engine rpm and temperature are significantly lower. Thus the sizing criteria are low and high cycle fatigue, crack propagation, and the effects of rotor burst. Creep is relevant only to a few components in the high pressure turbine and at the rear of the high pressure compressor and the creep life required is only a few hundred hours.

However, for the supersonic engine maximum $\mathrm{rpm}$ and engine temperature occur during the cruise phase so that creep becomes the main driver in sizing the bulk of the engine with creep life requirement measured in terms of thousands of hours.

The cruise temperature at compressor exit and turbine entry are at the same level as the maximum temperatures on todays subsonic engines so that significant improvement in creep performance over todays materials is required if we are to avoid major weight problems. Today considerable reliance is being placed in the development of various advanced metallic materials such as titanium aluminide, silicon carbide reinforced titanium or titanium aluminide. These materials offer good temperature capability, creep resistance and good specific strength.

On the basis of todays knowledge of our current materials and these new materials our best assessment of the technologies/materials to be used for the next generation of supersonic engines is, Figure 11:-

- Organic matrix carbon reinforced composites for the front structural casing.

- Titanium aluminide for the low and high pressure compressor vanes and casing.

- Silicon carbide reinforced titanium for the low pressure compressor spool and for the fan blades, disc and frame.

- Silicon carbon reinforced titanium aluminide for the high pressure compressor spool.

- Hastelloy for the combustion chamber.

- Improved powder metallurgy for the high pressure turbine disc.

- Improved single-crystal technology for high pressure nozzles and blades.

- Titanium aluminide for the low pressure turbine nozzles and casing and for the turbine exhaust case.

- Improved powder metallurgy for the low pressure turbine discs. 
For the systems considerable savings in weight will result from the use of modern flight deck display technologies, and the use of digital computers and data highways, to provide the control architecture.

Using these standards we have designed a datum aircraft to use in our evaluation. This is shown in Figure 12 and is sized to carry 280 passengers, 5,500 nautical miles with a cruise Mach No, of 2.05 . Physically the aircraft is some 50\% larger than Concorde.

This datum aircraft differs notably from Concorde in a number of key ways. The most obvious change is in the use of an additional horizontal lifting surface, in this instance a foreplane or Canard. This is required in order to give improved pitch control of the aircraft, both in terms of the speed of response to pitch change demands in low speed, low altitude flight and also in reduction of trim drag in cruise.

Also leading edge devices are a part of the datum design to improve low speed aerodynamic performance. This benefits the aircraft in two ways, firstly improved fuel burn in the low speed phases of flight, and secondly in better performance in take-off terms that will contribute to a better noise characteristic.

Perhaps the biggest difference is in the powerplant area. For this datum aircraft study we have used a derivative of the 0lympus engine of Concorde. This derivative is a by-pass engine, with a by-pass ratio of 1.5 in order to reduce exhaust velocity, and hence reduce noise. It is also equipped with an ejector silencer system based on model and flight test experiments carried out in the UK some 10 years ago.

As an interesting exercise we have studied the effect of such technology improvements on a Concorde sized aeroplane, that is a 100 seater aeroplane, Figure 13. If we apply exactly the same airframe technology used for Concorde but put on the better engines and the noise treatments required to meet todays FAR 36 Stage III noise requirements, the range of Concorde would be reduced from its current 3,500 nautical miles to something less than 3,000 nautical miles. But with the application of the assumed levels of technology for our datum aeroplane, the range would be increased to over 5,000 nautical miles, a fairly impressive

improvement. Also shown is what I have called "Todays Technology", i.e. the level of technology that we could confidently use if we launched the programme now. This would give a range of some 4,500 nautical miles. This gives a good feel for the way the airframe technologies have advanced since Concorde was designed.

An initial attempt has been made to assess the costs of the datum aeroplane that we have been studying and this, coupled with the assumed technology standards, has enabled us to make an initial assessment of the likely operating costs. This study shows that fare levels would have to be more than $15 \%$ higher than todays subsonic fares in order to cover costs and provide a return on investment. On the basis that a $15 \%$ fare premium would be acceptable and would result in a likely requirement for 1,000 aircraft, the technologies that would be required in order to bring the fare premiums back to the 15\% level have been assessed. This suggests that in supersonic cruise performance we need to see a further 15\% improvement and this would be shared between the airframe in the shape of the supersonic cruise lift/drag ratio, and for the powerplant in terms of its SFC. Our belief is today that such improvements are in fact achievable. Figure 14 brings together the various technology standards mentioned. 


\section{TIMESCALES}

To put the study programmes in perspective, it is worth identifying the timescales in which it is considered that such an aircraft would be introduced, Figure 15. Based on today's knowledge the earliest likely point for entry-into-service of such an aeroplane is around the year 2005. Bearing in mind the complex nature of a supersonic aeroplane and its certification process, such an entry-into-service date requires a significant effort to be put in from about 1995, with the definitive configuration and real programme go ahead in 1998. A key factor in the whole programme is establishing the requirements in terms of environmental impact, such as airport noise and emissions into the upper atmosphere, and before the project could go ahead in a serious business sense the necessary international standards and legislation need to be in place, or at least sufficiently well understood for confidence in eventual legislation to be gained. This is dealt with in more detail later.

\section{COLLABORATION}

If our assessment of the likely market is reasonably accurate we are looking at a world fleet of second generation supersonic transports reaching between 500 and 1,000 aircraft by the year 2030 . Today, the consensus is that this size of market would not support more than one successful programme. There is therefore considerable activity centred around the possibility of collaboration between the potential players.

Collaboration on large civil aircraft is not new. Indeed Concorde itself was a major collaborative effort between France and Great Britain and was the first such major collaboration in the civil field. Four main companies were involved, in the UK British Aircraft Corporation and Rolls-Royce, and in France Sud Aviation and SNECMA.

Since that time other collaborative ventures have taken place, notably Airbus Industrie in Europe.

There are initiatives already in place which have been well publicised over the past year or so. In summary, British Aerospace and Aerospatiale have entered into a three year period of collaboration, covering market analysis to determine the likely fleet size and a series of programmes aimed at studying the various technologies that will be required to produce such an aeroplane. Also British Aerospace and Aerospatiale are collaborating with Boeing, McDonnel Douglas and Deutsche Airbus in a similar activity, again covering market analysis, but in the technical areas studying more limited topics. In particular they are carrying out an assessment of the various environmental issues and the problems that could be associated with certification of a multi-national aeroplane. Equally, in this collaboration, a number of business topics are being studied primarily associated with activities that would be required to set up a large collaborative project, possibly involving European industry together with America and Japan.

In the same way collaborative groupings are in place on the engine activities. Rolls-Royce and SNECMA in Europe have an MOU covering supersonic transport engine studies and in the USA General Electric and Pratt \& Whitney have formed a joint activity on engines for this new aircraft.

\section{TECHNOLOGY DEVELOPMENT}

In parallel with the work going on in the collaborative studies, there is a considerable level of research activity in Europe, America and 
Japan, seeking to improve technology standards. This activity covers every aspect of the airframe and engine, Figure 16.

Much of this activity is aimed at improving our knowledge of the basic technologies involved in a supersonic transport aeroplane,but attention is also being paid to ensuring that costs in manufacture will be kept. to a minimum. In parallel the overall project design is being reworked continuously to validate the results of the research work and to evaluate the improvement that can be made relative to our datum aircraft.

\section{ENVIRONMENTAL ISSUES}

Three major topics dominate the environmental scene insofar as a second generation supersonic transport is concerned. These are airport noise, sonic boom and emissions into the upper atmosphere.

The problem of aircraft noise is uniquely different for a supersonic transport aircraft. In order to provide good performance at supersonic cruise conditions a low cross sectional area powerplant with a high velocity exhaust is necessary. Typically this will give exhaust velocities at take-off of around $800 \mathrm{~m} / \mathrm{s}$ and this would give unacceptable noise levels. The Olympus engine on Concorde gives $900 \mathrm{~m} / \mathrm{s}$ at take-off. Modern turbofans with by-pass ratios of around 5 or 6 give exhaust velocities of perhaps half of that level and this results in possibly $20 \mathrm{~dB}$ improvement in noise level, Figure 17.

There are two options being studied to deal with this problem. Firstly, the use of jet noise suppressors which essentially mix external air with the exhaust gases to reduce overall flow velocities. Various experimental programmes have demonstrated that noise reduction of this order can be achieved, but at the expense of significant thrust losses and considerable weight. The second option is the so called variable cycle engine that has the ability to adapt its flow patterns so that it operates as a low by-pass engine in cruise, but as a high by-pass engine at low speeds.

In the event it is likely that a combination of the two concepts will be used.

The challenge of the sonic boom is much more difficult to deal with. Experience with Concorde has shown that very low levels of overpressure (approx. $.25 \mathrm{lb} / \mathrm{ft}^{2}$ ) at the ground can cause problems. The primary boom on Concorde gives overpressures an order higher than this, around 2 $\mathrm{lb} / \mathrm{ft}^{2}$. Although the aircraft configuration can be adapted to reduce the overpressure, and equally important the rate of rise of pressure, such adaptations are at a significant and unacceptable cost in terms of cruise performance. To date our studies clearly suggest that supersonic flight over populated land masses will not be tolerated.

Also receiving considerable attention, and publicity, is the topic of emissions, especially of nitrogen oxides (nitric oxide and nitrogen dioxide) known as "NOX", into the upper atmosphere, and in particular their impact on the ozone layer. This is a very complex subject and one where our understanding of the physical and chemical processes involved is not complete. 
Figure 18 shows how the concentration of ozone varies with altitude in the mid latitudes, with the peak concentration at around $23 \mathrm{~km}$ altitude the so-called ozone layer. Also shown are the optimum cruise altitudes for supersonic aircraft at various Mach Nos., as well as the subsonic fleet. As can be seen supersonic aircraft exhaust emissions occur in the ozone layer itself.

The ozone layer is that part of the atmosphere that provides us with shielding against most of the sun's ultraviolet light - which can cause skin cancer, eye problems and depress the immune system of animals (like us) as well as affecting plants (which might be agriculturally important crops).

Concern about the stratospheric effects of engine emissions first arose in the early 1970 's during Concorde's development (and development of similar American and Russian aircraft). Based upon the rather limited knowledge of atmospheric chemistry at the time, the consensus was that any ozone depletion would be small. Of course these forecasts have never been tested because the number of supersonic transports flying has remained so small as to have a negligible effect on ozone.

Since the mid $70^{\prime} \mathrm{s}$ concern for the ozone layer has focused on the effects of chlorine (and bromine) from the now infamous CFC's and similar chemicals but with the current interest in a second generation Supersonic Transport has again brought NOX back into focus.

Both NOX and chlorine (and bromine) react with ozone and destroy it. Reactions between NOX and chlorine themselves, however, result in molecules that do not attack ozone. Conversion of these 'reservoir' molecules back into ozone destroying forms, can take place on the surfaces of stratospheric ice crystals and sulphur particles - leading for example to the Antarctic ozone 'hole' and perhaps to the low amounts of ozone measured (by European and American scientific expeditions) over mid latitudes of the northern hemisphere. Also taking place on the surface of those ice or sulphur particles may be reactions that convert NOX into a form that does not attack ozone.

Recent work at the University of Cambridge has concluded that ".... the direct impact of high speed civil transport is likely to be much less than previously thought ....."

Much of this activity is centred around a NASA co-ordinated study which is building on work begun when the CFC problem was realised in the late seventies. (That work led to the Montreal Protocol of 1987 and is continuing as the Protocol is reviewed). Prominent scientists from Europe are part of this activity. Equally there are similar studies running in Europe, although in a less well co-ordinated fashion.

Also key to this problem is quantity of pollutant created by the engine. Emissions from an engine are characterised by an 'Emission Index' (EI) the amount of pollutant (in grams) produced per $\mathrm{Kg}$ of fuel used. In the case of Concorde the EI during its cruising stage is about 19 - a figure probably not much different from todays subsonic aircraft. To ensure its effect on ozone is minimal Concorde's successor will need to have a much lower value - a figure of 5 is the target of work currently underway. 


\section{SUMMARY}

Technically I believe there is little doubt that a successor to Concorde could be put into service by 2005 to 2010 and that it would prove to be an attractive aeroplane for the fare paying passengers and the Airlines. However, there are many hurdles to be overcome before a decision can be made to launch such a programme.

A key issue is that of the environmental aspects in two areas. Firstly much work remains to be done by the world scientific community to continue the studies into atmospheric modelling and chemistry in order to establish robust models for the prediction of atmospheric changes far into the future. This will permit world legislators to agree an allowable emission level for a new supersonic aircraft. Secondly, more work remains tobe done on airport noise. Within the ICAO framework the topic of airport noise is being studied as part of their normal cycle of review of noise legislation. It is anticipated that both of these activities will come to fruition by 1995 or 1996.

Today we are hopeful that the outcome of this work will be legislation setting limits that are achievable for a new supersonic aircraft. If the limits set are too demanding then there will be no project launch.

Equally important in the decision process is the need to be confident that there is a sound business case for the project such that the manufacturers and Airlines can make sensible returns on their investment.

In conclusion I should return to the title of the lecture "Prospects for a Second Generation Supersonic Transport." Concorde has shown that a supersonic aircraft can provide an attractive and reliable service.

Technology advances since then should provide a second generation aeroplane able to fly between Europe, Asia and America on most of the important city pairings. Provided that development and manufacturing costs are held to reasonable levels then an aeroplane attractive to the manufacturers, airlines and customers should result.

It is also worth noting that a supersonic aircraft is particularly well suited to the trans-atlantic and trans-pacific routes which will be the most used routes in the early part of the next century.

Overall, therefore, I conclude that the prospects for a second generation supersonic transport can be judged at this early stage as favourable. There is, however, one very important reservation, and that is the future of legislation on environmental issues.

\section{ACKNOWLEDGMENT}

I acknowledge the permission given by British Aerospace to publish this paper. 


\section{Concorde}

- 10 tonnes payload over $3500 \mathrm{~nm}$ at $\mathrm{M}=2.05$

- Operates within the existing traffic patterns

- 49,000 supersonic flights in service

- Good safety and reliability record

- Well liked by passengers (BA load factor typically 70 - 80\%)

But

- Does not meet current noise regulations

- Operates at high premium fares

- Sonic boom unacceptable over populated areas

- NOX emissions high compared to todays subsonic aircraft

- A long, high cost, high risk development programme

fig. 1

\section{Requirements for Second Generation Supersonic Transport}

- Aircraft must be capable of earning a satisfactory commercial return for both manufacturers and airlines

- Aircraft must match route patterns and airline system of 21 st century at normal dispatch reliability

- Environmental requirements for noise and emissions must be met

- Programme costs and risks must be controlled 
Forecast Annual Traffic Growth Rates Long Haul

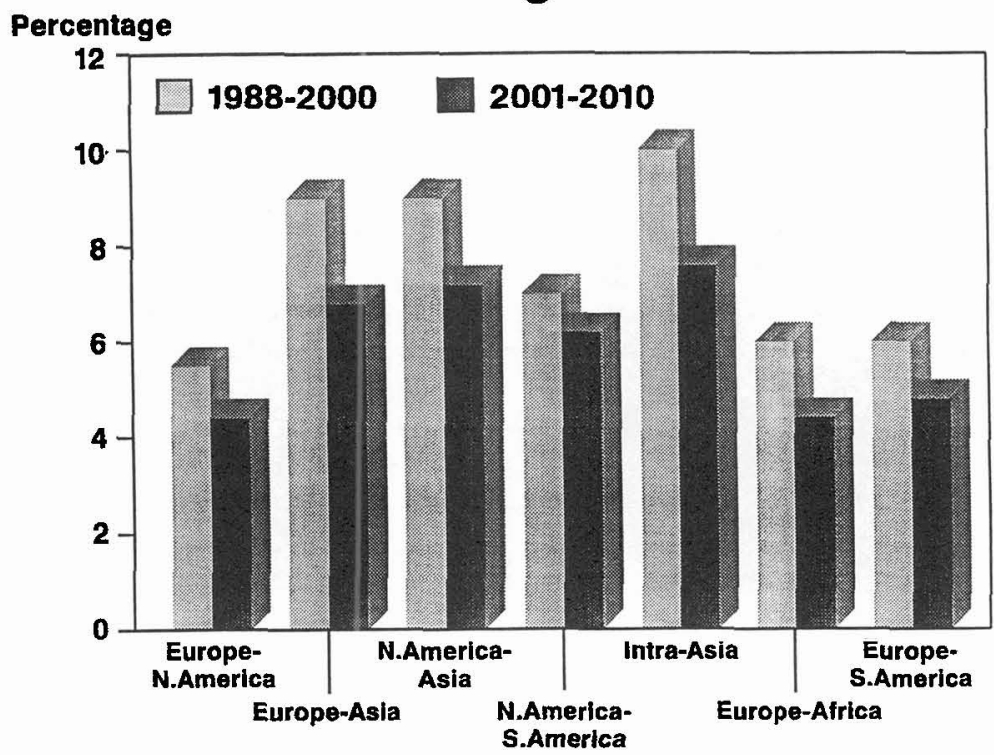

fig.3

\section{Traffic Growth Projection 1988-2030}

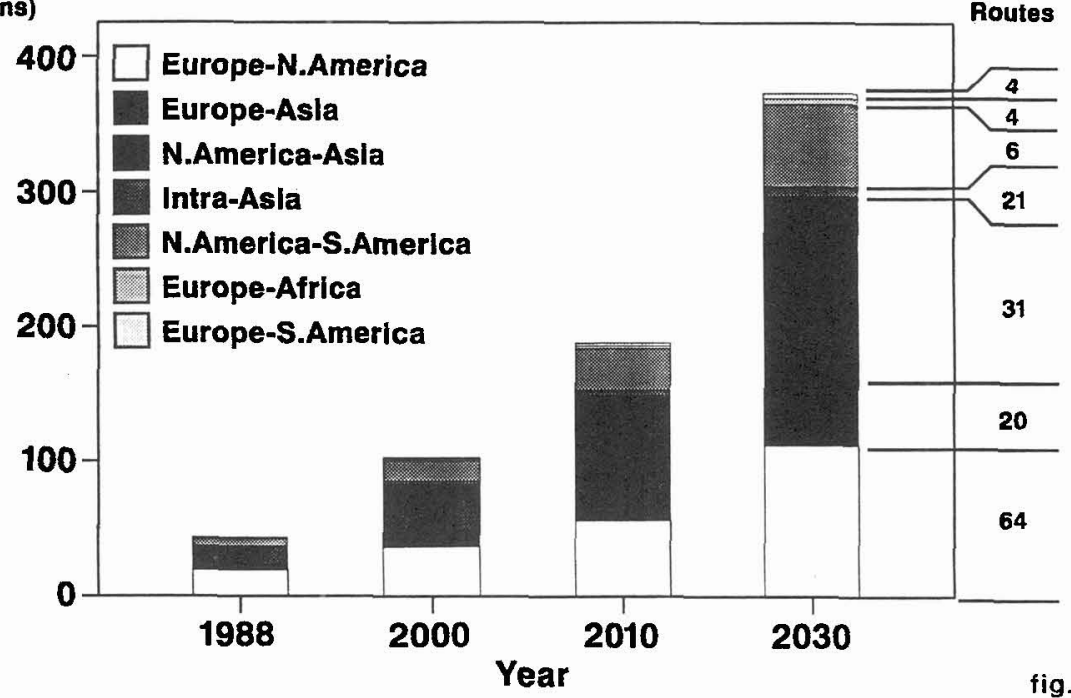

fig. 4 


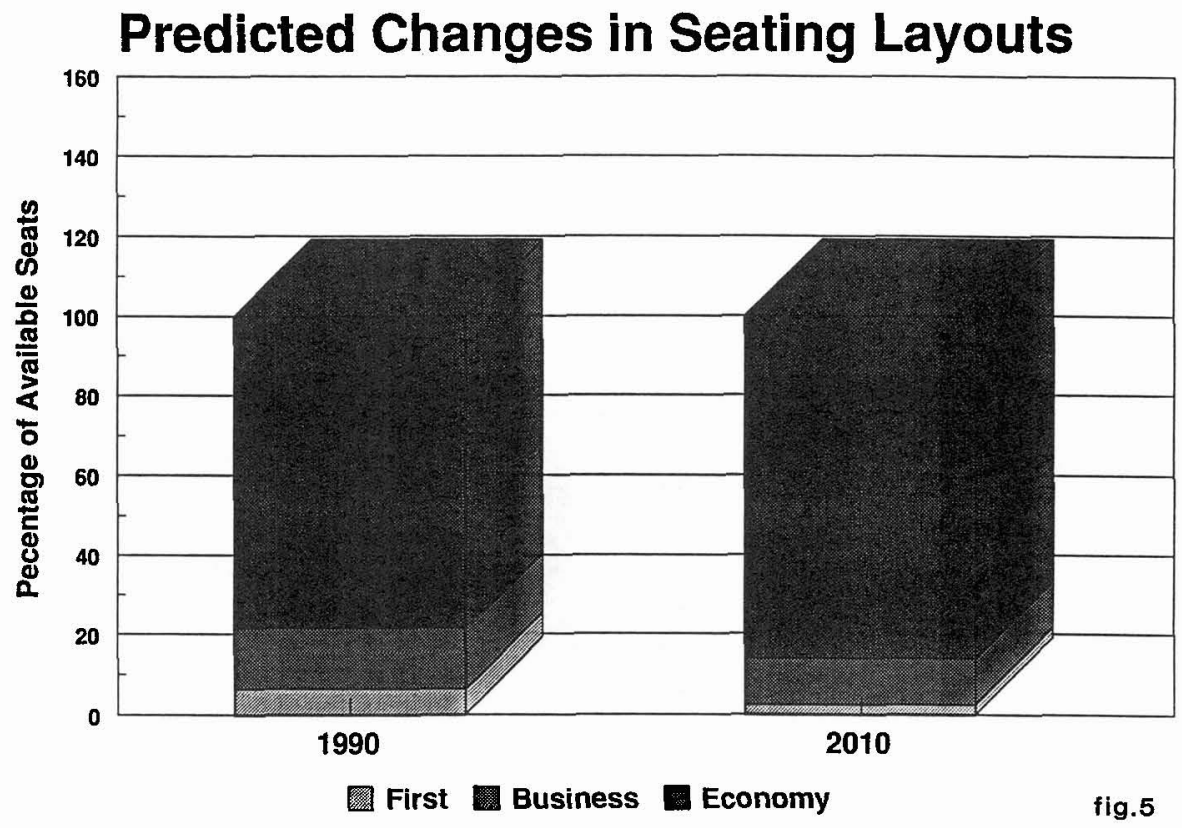

\section{Reduction in Traffic with Increasing Fare Levels}

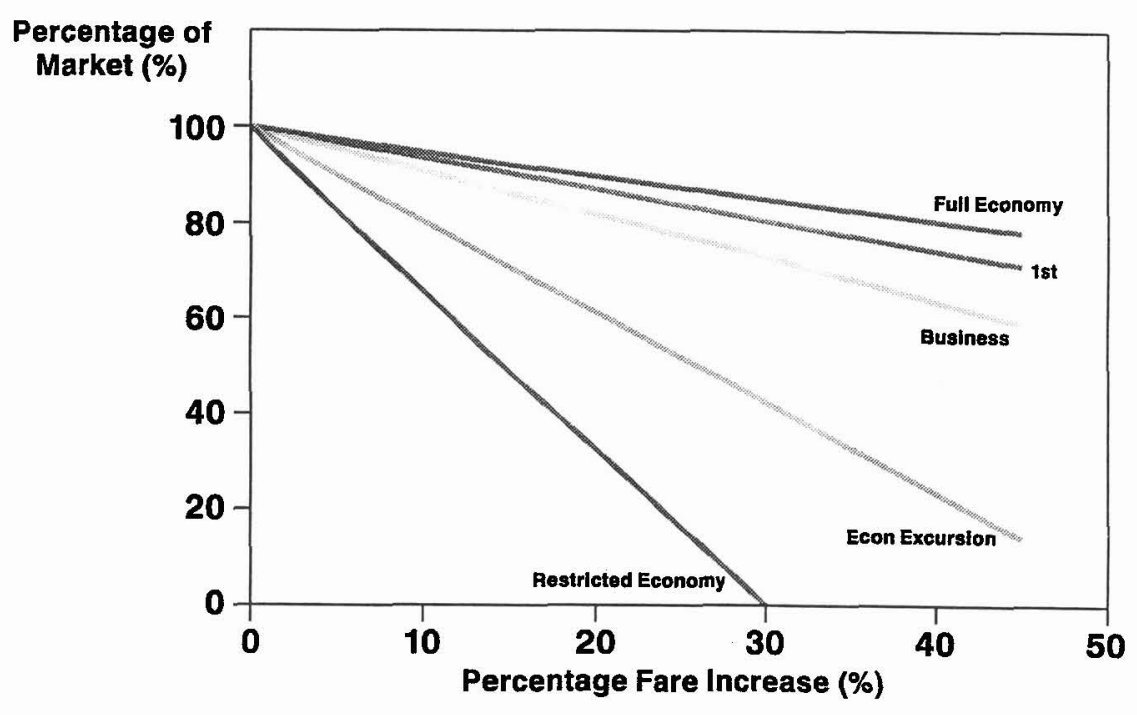

fig.6 


\section{AST Passengers and Fare Classes in $\mathbf{2 0 3 0}$}

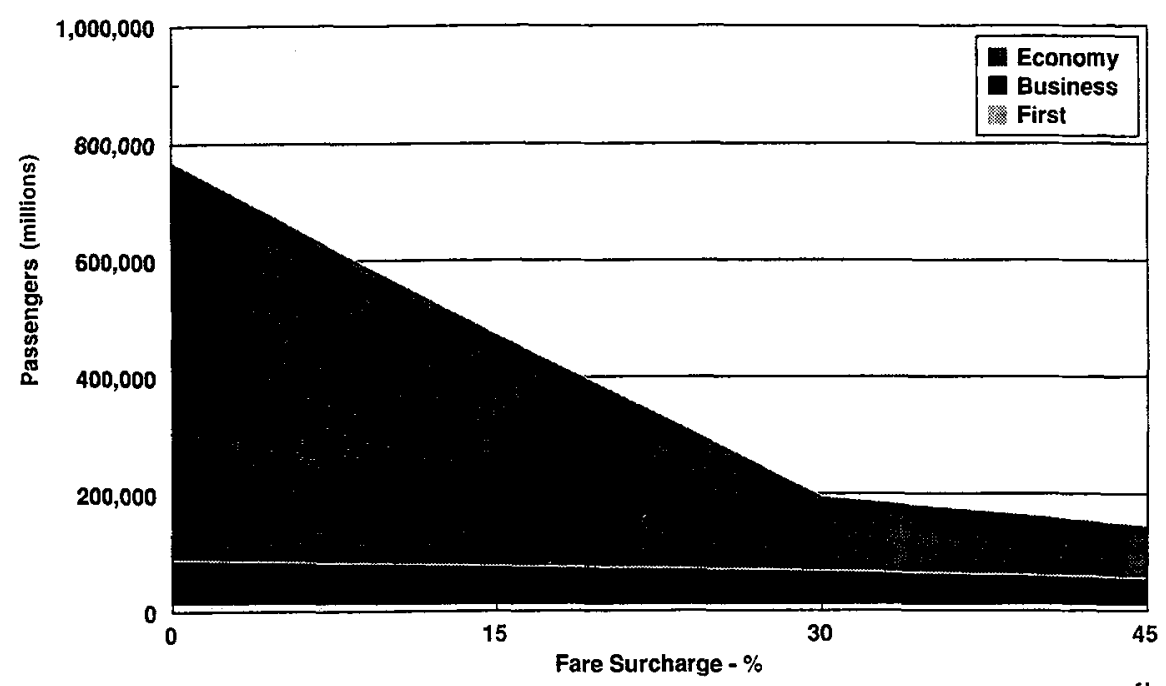

fig.7

\section{Market Requirements in $\mathbf{2 0 3 0}$}

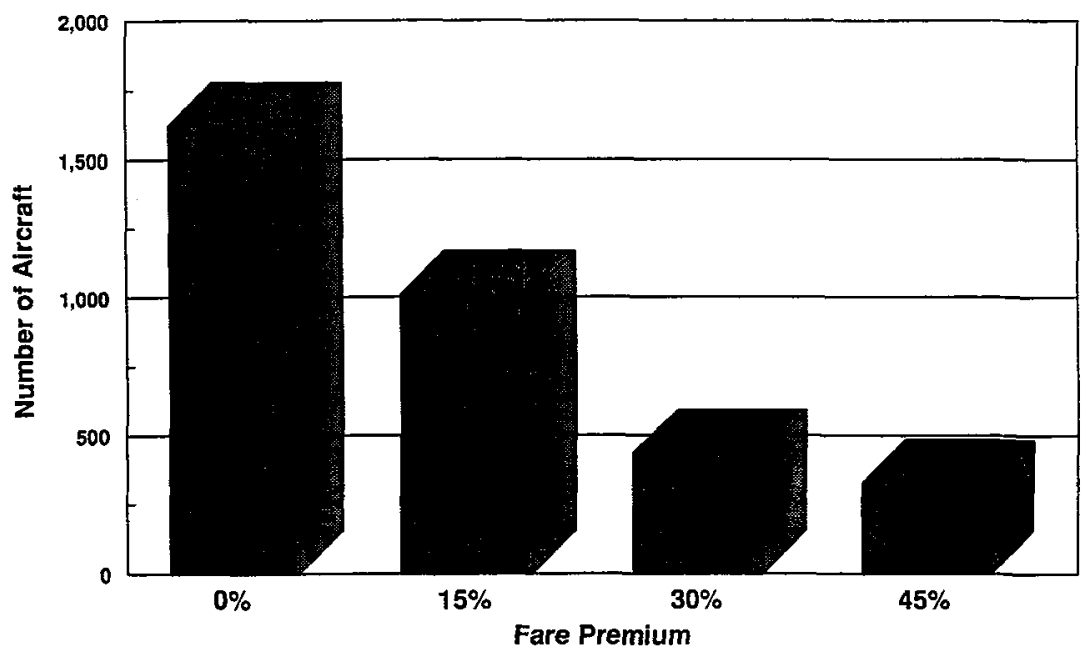

Top 150 Routes 280 Seat AST

fig.8 


\section{Advanced Supersonic Transport Study Technology Standard Assumed for Datum Aircraft}

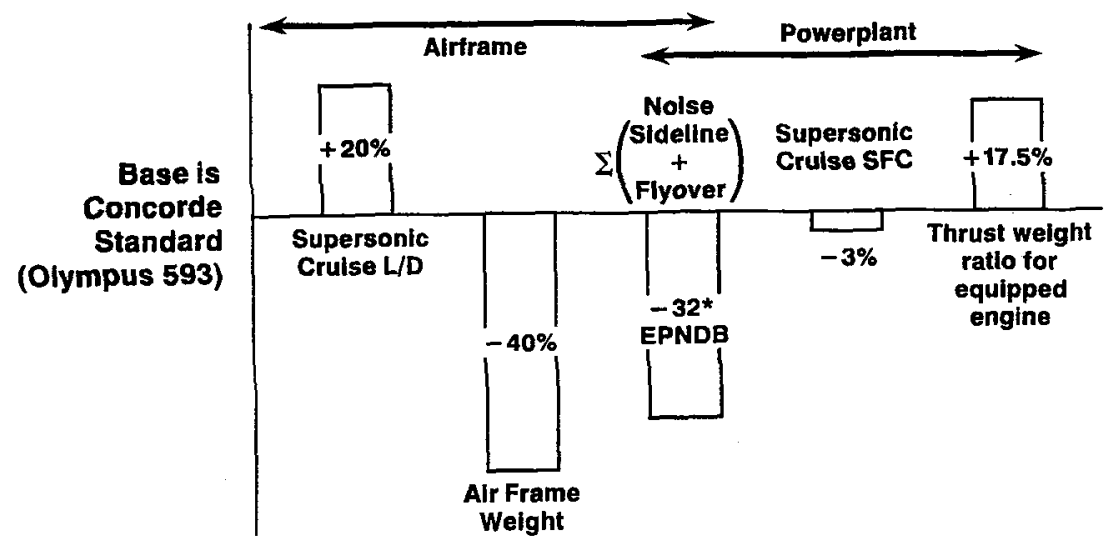

* Meets far part 36 stage III (no margins)

fig. 9

\section{Advanced Supersonic Transport Study Datum Aircraft}

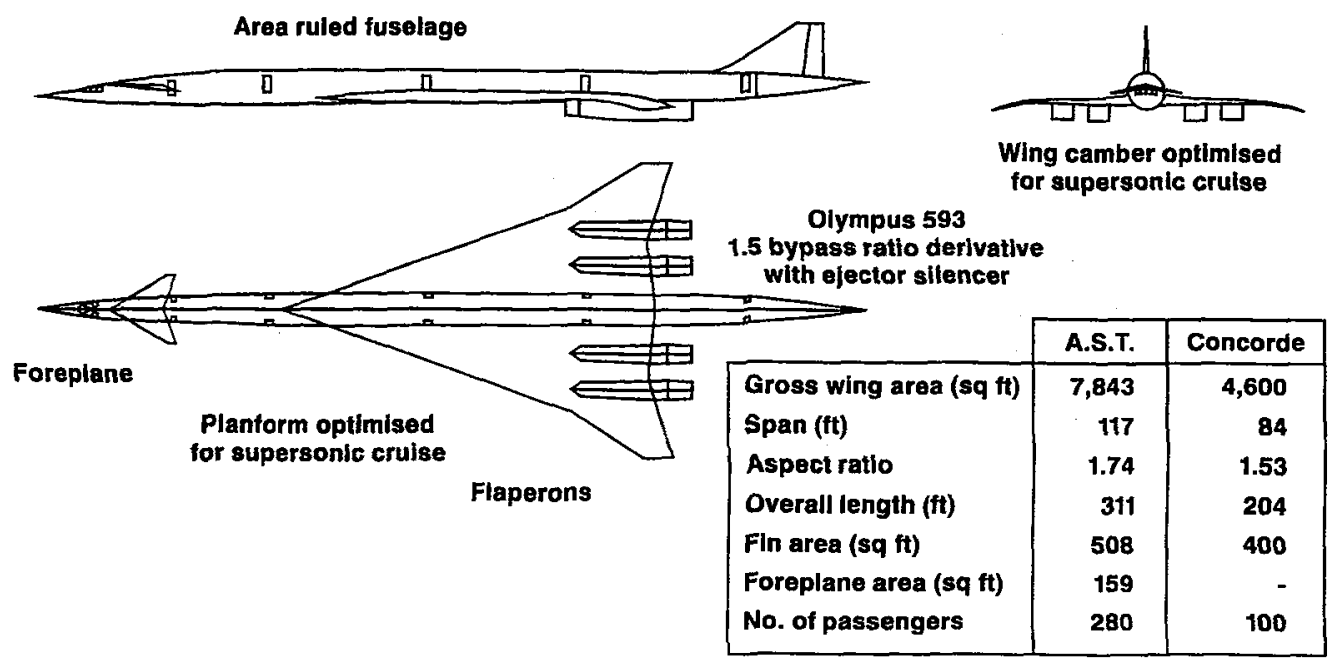

fig. 10 


\section{Typical Operating Temperatures vs Cruise Mach No.}

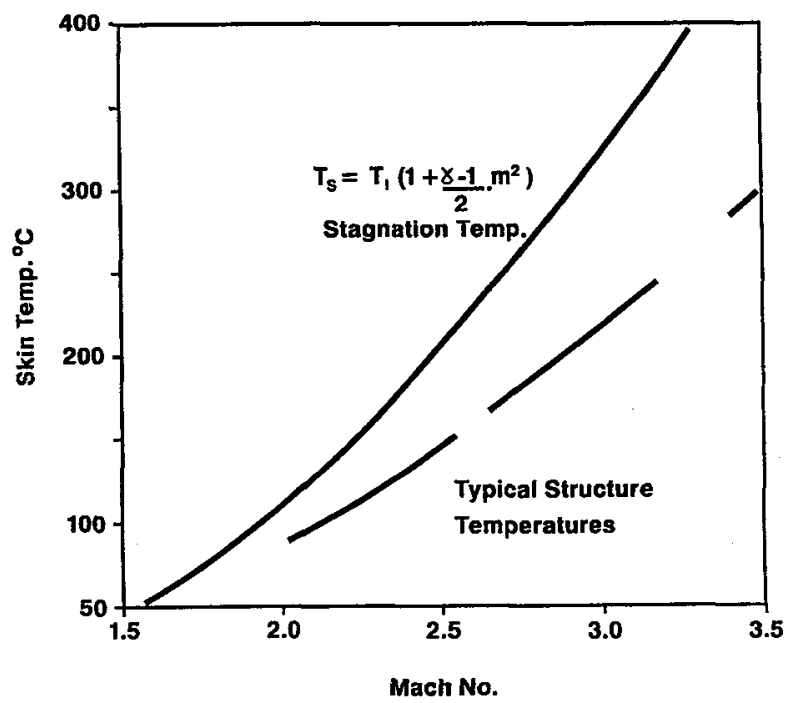

fig. 11

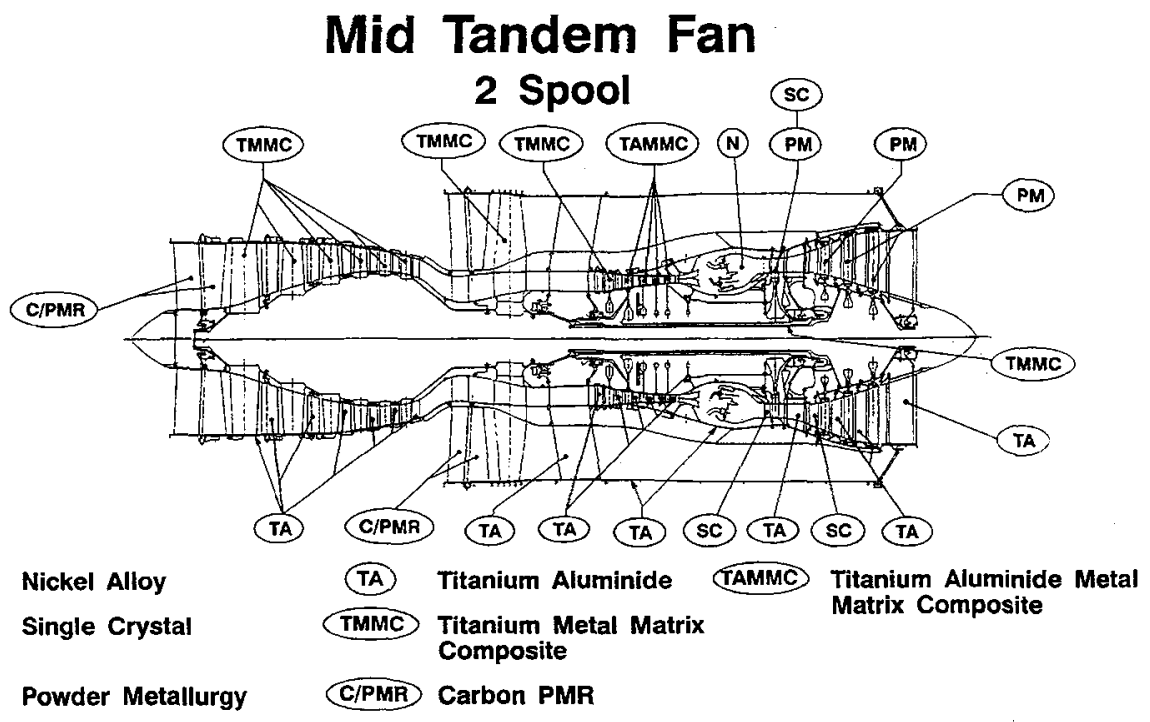

fig. 12 


\section{Advanced Supersonic Transport Study Feasibility of Achieving AST Technology Standards}

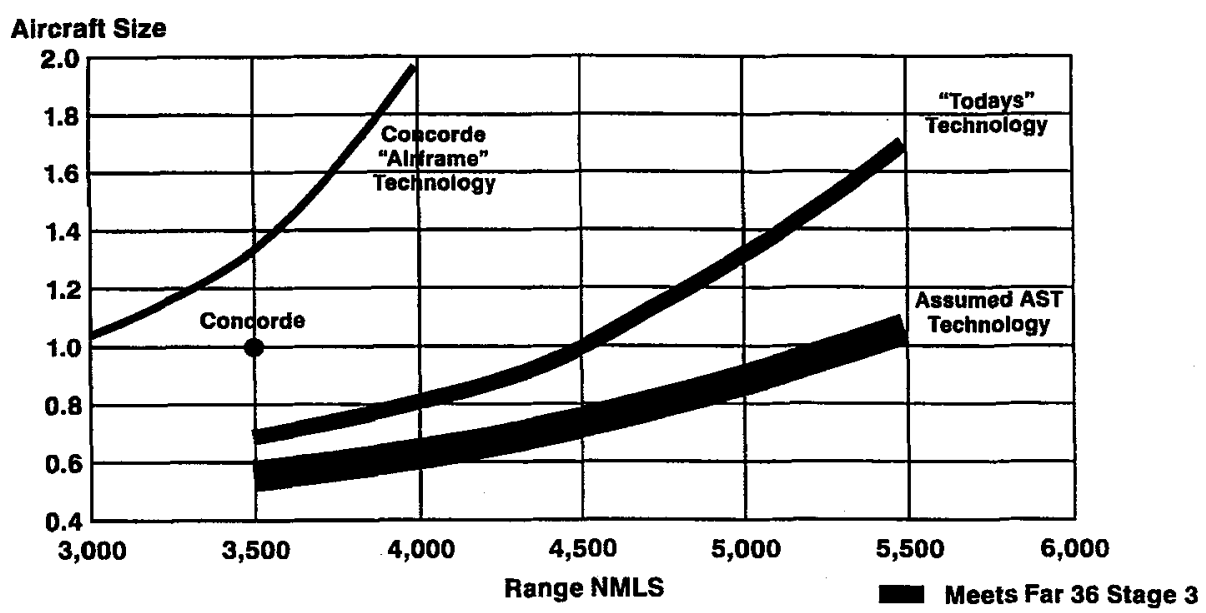

fig. 13

\section{Advanced Supersonic Transport Study Technology Standards Relative to Concorde}

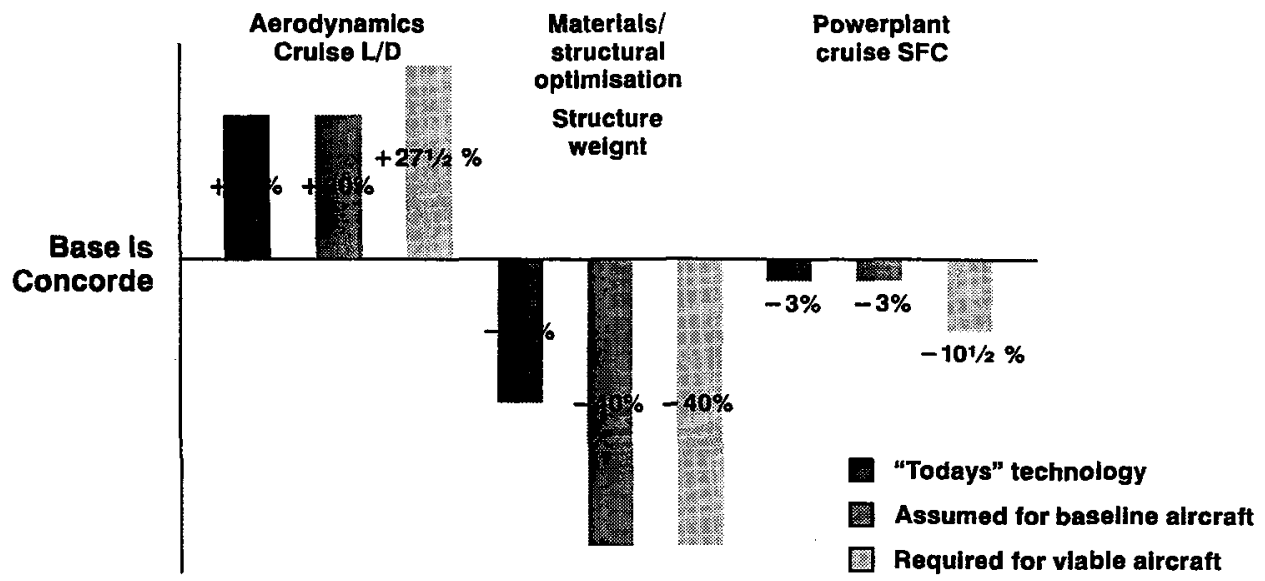

fig. 14 


\section{Supersonic Planning}

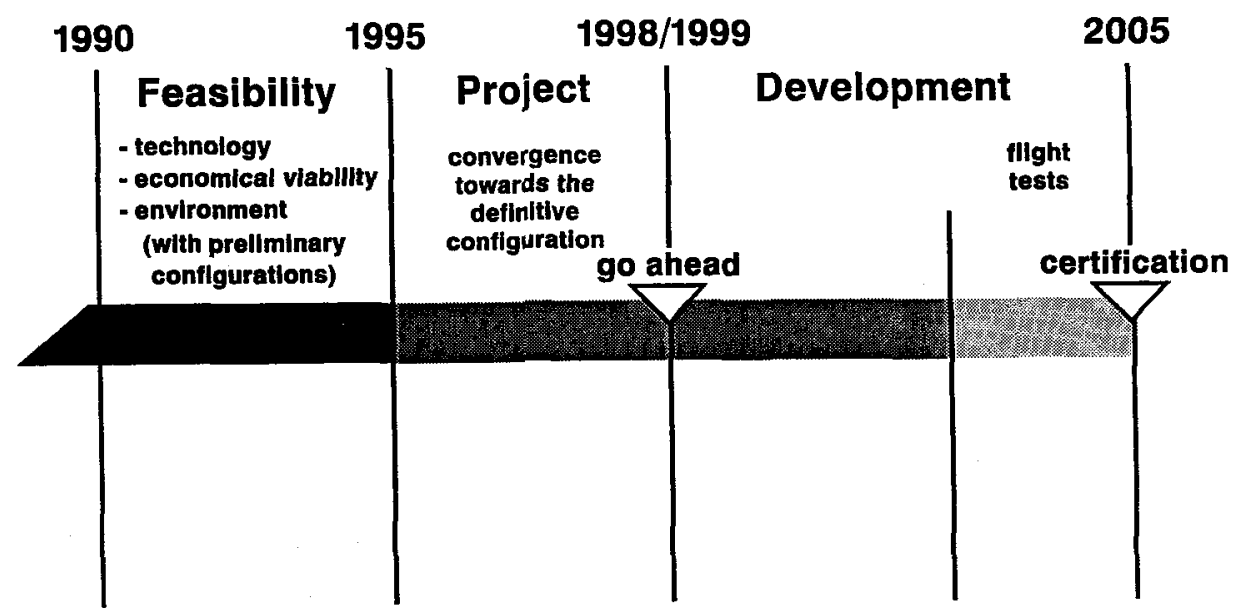

fig. 15

\section{Aircraft Research Topics}

Aerodynamics

- Drag reduction

- Design methodology

- Powerplant aerodynamics

- Aeroelastics

Systems

- Control Actuation Design

- Flight Deck/Avionics

- Alrcraft systems (heat management, fuel, de-icing etc)

- Cabin environment and safety

Structures/Materials

- Selection of materlals for major components

- Material tests - design studies - manufacturing techniques/costs

Powerplant

- Varlable cycle engines

- Silencing techniques

- Emissions reduction 


\section{Relation Between Noise and Exhaust Velocity}

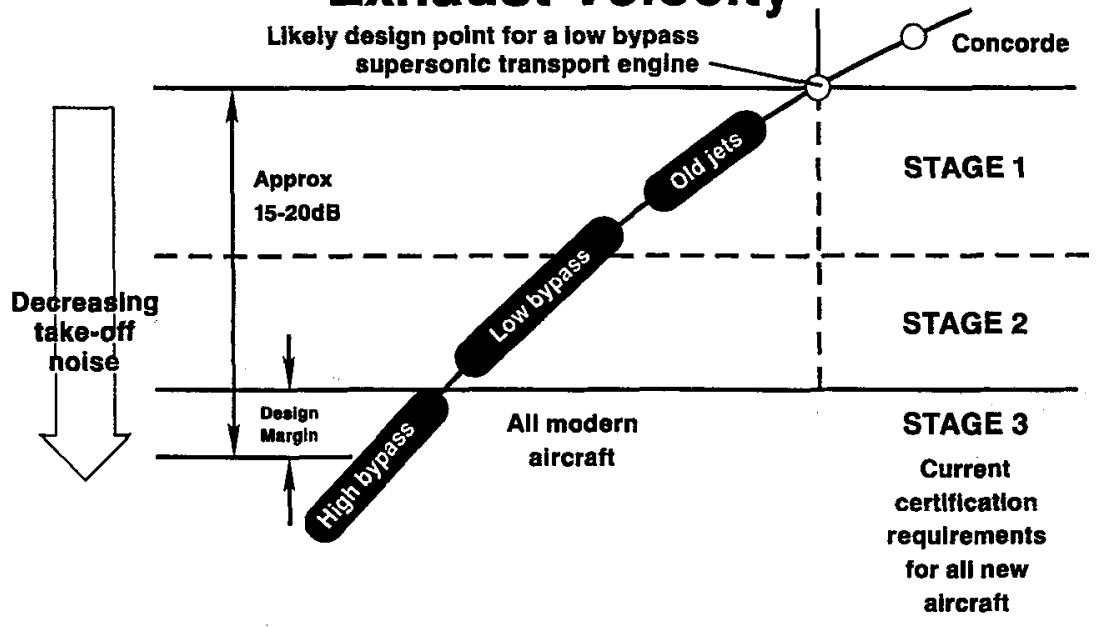

\begin{tabular}{|c|c|c|c|c|c|c|c|}
\hline 200 & 300 & 400 & 500 & 600 & 700 & 800 & 900 \\
\hline \multicolumn{8}{|c|}{ Exhaust jet velocity $(\mathrm{m} / \mathrm{s})$} \\
\hline
\end{tabular}

fig. 17

\section{Atmospheric Ozone (Mid-Latitudes)}

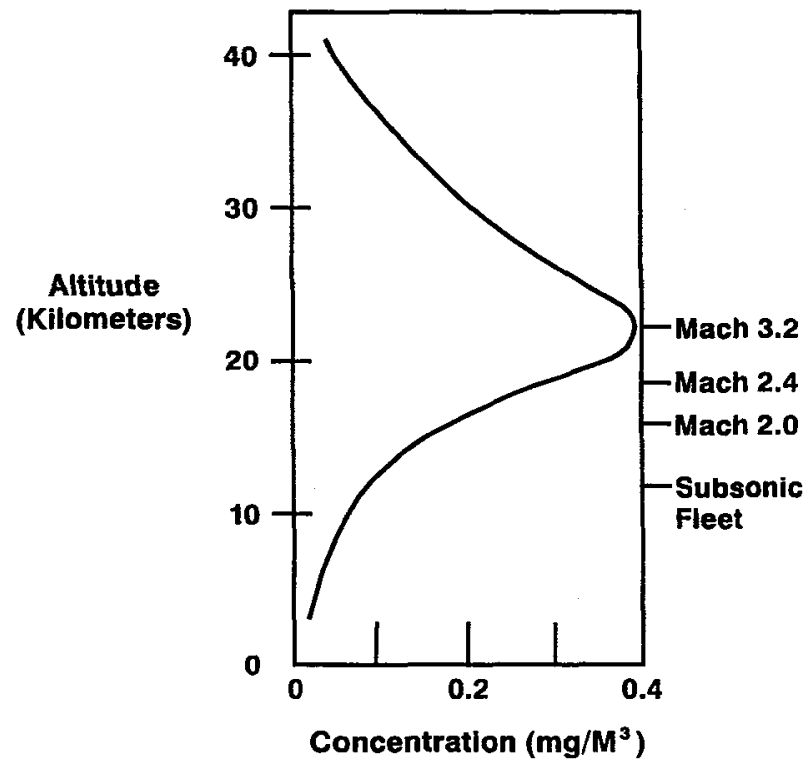

fig. 18 